\title{
Sllustres Collegas
}

Cumprindo o dever que resulta do disposto no art. 29 do Decr. n. 8.659, de 5 de Abril de 1911, venho relatar o que occorreu no Conselho Superior de Ensino; nas sessões de 1 a 10 do corrente. Dividirei a minha exposição em nove partes: $10^{a} \mathrm{Ca}$ racter da personalidade jutidica; . $^{a}$ Extensão da autonomia administrativa; $3 .{ }^{a}$ Responsabilidade fiscal das Congregações, do Director e do. Thesoureiro; 4. ${ }^{a}$ Extensẫo da taxação autonoma; 5 . $^{\mathrm{a}}$ Extensão da autonomia didactica; $6 .{ }^{2} \mathrm{O}$ Gymnasio D. Pedro II e os gymnasios equiparados; 7.a Questões adiadas; $8 .^{\mathrm{a}}$ Outras questōes relevantes; 9. ${ }^{3}$ Recursos e reclamações.

\section{I}

\section{Caracter da personalidade juridica}

Estudando a personalidade juridica dos Institutos a que se refere o citado Decreto, o Conselho ponderou o seguinte:

1. Que a Lei Organica manteve, e não podia deixar de manter, para esta Faculdade, assim como para os outros Institutos de ensino, a cargo da administração publica, o caracter de fundações officiaes, posto que investindo-as da personalidade juridica;

2. Que a Lei não quiz dár nem á Congregação dos Professores, nem aos estudantes, o caracter de sujeito dos bens, permantecendo este caracter no proptio instituto, cono abstraç̧ão personificada e como corpo de mão morta; 
3. Que, usando do termo - «Corporações" - a Lei empregou uma analogia, para tornar claro que os institutos, por seus administradores, não pódem alienar bens sem autorisação do Governo, ad instar das corporações de mão morta, na fórma da Lei de 9 de Dezembro de 1830;

4. Q Que o termo - «patrimonio» - está tomado no seu sentido generico, para exprimir a receita dos institutos, quer a consistente no uso do proprio nacional, em que funccionam, e nos materiaes, laboratorios e bibliothecas, quer a consistente nas subvenções votadas pelo Congresso Nacional, quer a consistente nas taxas, quer a consistente em doações e legados.

Em conclusão, verificou-se que esse patrimonio nada mais é do que a receita de uma fundação official, investida de personalidade juridica e autonomia relativa.

Em summa, o sujeito do direito dos bens não é a corporação docente, nem a corporação discente : aquella, isto é, os professores ordinarios e extraordinarios, além das funcções disciplinares, intervem na gerencia da receita da fundação; esta, isto é, os estudantes habilitados em exame de admissão, têm, não só o direito á matricula, como todos os mais direitos decorrentes da qualidade de destinatarios de uma fundação official.

\section{Extensão da autonomia administrativa}

Passou o Conselho a encarar a extensão da autonomia das corporações docentes na gerencia do referido patrimonio, ou antes, a extensão da autonomia administrativa das Congregações na applicação da receita dessas fundações. Fixando as regras desta autonomia, ponderou o Conselho:

1. Que a Lei Organica, no art. 10, declara muito terminantemente que $« 0$ patrimonio de cada instituição será administrado pelo respectivo director, de accordo com as Congregações e com o Conselho Superior do Ensino»; 
2. Que a Lei Organica, no art. 28, declara, ainda mais terminantemente, que "toda a parte administrativa ficará a cargo do director, havendo recurso de suas deliberações para o Conselho Superior do Ensino";

3. Que a clausula "de accordo com a Congre. gação», do art. 29, letra $b$, não dá, portanto, á Congregação funcções deliberativas em relação á administração do patrimonio, porém funcções consultivas. que, sem embargo de poderem ser, não só provocadas, como tambem de iniciativa ou de indicação, de modo algum afastam do director a exclusiva responsabilidade da deliberação.

\section{I I}

\section{Responsabilidade fiscal}

Firmados estes principios, passou o Conselho a estudar a responsabilidade fiscal, quer em relação ás Congregações, quer em relação aos directores, quer em relação aos thesoureiros; e ponclerou:

1.० Que as Congregações não têm responsabilidade fiscal alguma, mesmo porque as suas funcções consultivas, comquanto possam ser até de iniciativa ou de indicação, não afastam do director a funcção deliberativa;

2. Que a personalidade juridica dos Institutos de ensino não lhes tira $o$ caracter de fundações creadas e mantidas pela aủministração publica, e, portanto, não os subordina, como as fundações a que se refere a Ord. L. I, tit. 62, ao Juizo da Provedoria, ou á verificação judiciaria de contas, quer nas jurisdicções estaduaes, quer na jurisdicção federal ;

3. Que o. director dos Institutos, segundo as regras estabelecidas desde os Decrs de 8 de Outubro de 1828, 16 de Dezembro de 1830, e outros, prestará as suas contas ao Ministerio da Justiça e Negocios Interiores, segundo os regulamentos e instrucções da respectiva contadoria;

4. ${ }^{\circ}$ Que a responsabilidade fiscal dos thesoureiros é inilludivel, visto que estes recebem e guardam 
dinheiros publicos, são pagadores de conśignações, são, em summa, exactores fiscaes; e, portanto, na forma de Ordens do Thesouro e Avisos do Ministerio da Fazenda, devem prestar a sua fiança no Thesouro ou nas Delegacias Fiscaes, com todas as cautelas do processo fiscal, sendo que a falta ou irregularidade da prestação dessa fiança acarretam a rèsponsabilidade subsidiaria dos funccionarios que deixarem esse responsavel servir sem fiança ou com fiança irregularmente prestada.

\section{IV}

\section{Extensão da taxaşão autonoma}

Em seguida, o Conselho verificou que as Congregações se excederam na attribuição de lançar taxas e não foram uniformes no modo de comprehender essa attribuição; e então, ponderou o seguinte:

1. Que a Lèi Organica conferiu ás Congregações a attribuição não de crear taxas, mas a de lançar taxas, suppondo assim taxas já especificamente creadas ; taxas :

2. Que a Lei Organica especificou as seguintes

a) Taxa de matricula;

b) Taxa de certidão;

c) Taxa de bibliotheca;

d) Taxa de certificados;

e) Taxa de frequencia de cursos;

f) Taxa de inscripção para exames.

3. Que as abreviaturas - etc., etc. - da letra $f$ do art. $7 .^{\circ}$, por sua natureza, tendo uma significação restrictamente analoga á do enunciado antecedente, não pódem ter o effeito de conferir ás Congregações a attribuição de crear taxas, maximé sobre titulos de nomeação de professores e portarias de licença, que nem siquer são expedidos pelos Institutos, sobre outros titulos, taes como diplomas de bacharel, sujeitos ao sello de verba como titulos de direito, assim 
como sobre guias de transferencia, com effeito de prohibição, e sobre certidões, em que a fé publica do secretario tem de produzir effeitos completamente extranhos ao serviço do ensino:

t. Que tratando-se de contribuições arbitraveis. como a da especie contida na Lei Organica, a taxação autonoma das Congregações, como todas as taxações autonomas de serviços publicos de analoga natureza. dependem la approvação do Governo, mediante a revisão do Conselho Superior, no exercicio da funccão fiscal que the confere 0 art. $5 .^{\circ}$ da mesma lei.

\section{T}

\section{Extensão da autonomia didactica}

Quanto á autonomia didactica, o pensamento geral do Conselho $i$ o seguinte:

1. Que a propria Lei Organica, no art. 138 distingue as disposiçóes regulamentares das inherentes a intima economia, tanto en relação á autonomia administrativa, como em relação á autonomia didactica:

2. Q Que, sob este ultimo ponto de vistá, há a considerar, não só a organısação dos programmas, como a classificação das materias por séries e a coordenação das cadeiras por annos;

3. Q Que a organisação dos programmas, assim como tudo quanto possa affectar apenas a disciplina de cada Instituto, está contido na exclusiva autonomia das Congregações:

4. Que outro tanto não acontece quanto ás materias para o exame de admissão. e quanto á coordenação das cadeiras por annos, visto que, tendo a Lei Organica, no art. 71, garantido aos estudantes o direito de transferencia de um para outro Instituto, suppõe uma conformidade sob estes dous pontos de vista, nos Institutos similares, de sorte que, para este effeito, as deliberações das Congregações dependem da revisão do Conselho Superior. 


\section{O Gymmasio D. Pedro II e os Gymmasios equiparados}

O Conselho, em sua maioria, entendeu que diversa é a situação juridica do Gymnasio D. Pedro II e a dos gymnasios equiparados: os estudantes do Gymnasio D. Pedro II têm direitos decorrentes ra qualidade de destinatarios de uma fundação official, ao passo que os dos outros gymnasios não pódem transformar a equiparação, que é um attributo contingente, em identificação que produza do mesmo modo direitos adquiridos.

Os paes dos alumnos do Gymnasio D. Pedro II invocam a directa responsabilidade do Governo na organisação e funccionamento disciplinar do Gymnasio D. Pedro II; e dahi fazem decorrer o seu direito a que seus filhos, habilitados nesse Gymnasio, possam, independentemente do exame de admissão, ser matriculados nos Institutos officiaes de ensino superior. O Conselho, em sua maioria, não deixa de julgar procedente essa allegação; mas, quanto aos gymnasios equiparados, pensa diversamente, porque a equiparação não tinha o effeito de tornar directa e positiva a acção do Governo na organisação e funccionamento disciplinar desses gymnasios.

\section{I I}

\section{Questōes adiadas}

Das outras questões levantadas por esta Congregação, restam quatro, que ficaram sem solução definitiva, por diversas razões.

A relativa ás guias de transferencia para as Faculdades Livres e destas para as Faculdades officiaes: ficou adiada, porque já estando quasi a terminar o anno lectivo, é mais opportuno tratar deste ponto na reunião de Fevereiro.

As relativas á coordenação das cadeiras de Theoria do Processo e Pratica Forense, para que sejam leccionadas pelo mesmo professor, em dois 
annos consecutivos, e da cadeira de Medicina Publica, para que seja leccionada no ultimo anno: ficaram adiadas, por não haver opportunidade de resolver desde logo sobre isso, visto que a solução só será applicavel aos actuaes primeiro-annistas.

A relativa á coordenação da cadeira de Direito Romano no primeiro anno, e de Direito Publico no segundo: ficou adiada para tratar-se disso na reunião de Fevereiro, tanto mais quanto os actuaes primeiroannistas já estão no regimen do regulamento que veiu annexo á Lei Organica.

A relativa aos diplomas de bacharel e doutor. O nosso preclaro collega, dr. Reynaldo Porchat, com o talento que lhe é peculiar, buscou demonstrar que o diploma de bacharel, mesmo dentro dos moldes da Lei Organica, podia ser conferido pelas Faculdades; pois, além de ser um titulo de direito, consagrado na nossa legislação, tem ainda a significação de um premio honorifico por ter o estudante completado o seu curso, e, ao menos, com este ultimo caracter, a Faculdade tem autonomia para outorgal-o. Demonstrou elle que, nos nossos habitos, está a collação de gráus considerada como uma solemnidade, importando o despertar da responsabilidade profissional, assistido com essa commovedôra significação pelas familias dos alumnos, as quaes assim comprehendem o seu dever de auxiliar a acção disciplinar dos professores.

Eu affirmei, como já tinha manifestado nesta Congregação, que o diploma de bacharel não é um privilegio, mas um titulo de direito sujeito a condições de exercicio; e as leis administrativas tanto assim o consideram, que o exigem: como titulo para a investidura nos cargos de magistratura e ministerio publico, e para o direito de postular em juizo como advogado independentemente de provisão judicial; como titulo para o exercicio das profissões de medico e de engenheiro, que affectam, como profissões liberaes, não só o interesse privado, como o interesser social da conservação dos individuos, da segurança das obras publicas e construccões, da exactidão das medições, demarcações e partilhas geodesicas judiciaes, etc.; aliás, as leis financeiras incluem estes diplomas entre 
os titulos de direito e, como taes, os sujeitam a uma taxa especial do sello de verba.

Mas a Lei Organica revelou, na sua exposição de motivos e na substituição dos diplomas por certificados, o pensamento que a dictou. E, nestas condições, o Conselho, depois de haver affirmado que os estudantes do segundo anno em diante permanecem com o direito de exigir a collação de gráu e o diploma de bacharel em vez do certificado, resolveu representar ao Governo sobre a conveniencia de ser conferido o diploma de bacharel mesmo aos actuaes primeiro-annistas, que completarem o curso, e a todos os que, em identicas condições, se formarem nas Faculdades officiaes.

\section{VIII}

\section{Outras questōes relevantes}

O Conselho, interpretando o termo complexo«taxas de cursos geraes», do $§$ unico do art. 128 da Lei Organica, entendeu que essas taxas são as do art. 32, letra $e$ e do art. 33, letra $c$. da mesma Lei, como distinctas das taxas de frequencia a que se refere o art. $7 .^{\circ}$, letra $f$. O Presidente do Conselho resolveu suspender essa interpretação, por entender que não estava conforme ao pensamento geral da Lei Organica. tanto mais quanto os cursos livres a que se referem os arts. 32, letra $e$ e art. 33, letra $\boldsymbol{c}$. são antes cursos especiaes do que cursos geraes; em todo caso, declarou o Presidente que consultaria o Governo.

Sob consulta de professores do Gymnasio D. Pedro II, resolveu o Conselho que, conforme sempre se praticou, a lista triplice dos nomes propostos ao Governo para a nomeação de professor, deve ser organisada mediante votação uninominal em tres escrutinios; mas, ao que me consta, a Cungregação daquelle Instituto resolveu que essa votação uninominal deve ser feita em um só escrutinio, formada a lista na ordem dos votos então apurados. 


\section{X}

\section{Reclamacōes e recursos}

Relativamente a recursos, o Conselho deu provimento : a um, dos estudantes do Grmnasio D. Pedro II, sendo que o Presidente do Conselho suspendeu a decisão por entender ser contrária á Lei Organica; a outro, de um estudante da Faculdade do Recife, que, tendo sido reprovado em uma das cadeiras do primeiro anno, affirmava o seu direito a proseguir o seu curso pelo regimen antigo.

Relativamente a reclamações, o Conselho deixou de tomar conhecimento: de uma, dos estudantes de um gymnasio equiparado da Bahia, que allegavam. direitos adquiridos, e assim o decidiu o Conselho, por entender que, como corporação simplesmente administrativa, não tinha competencia para conhecer de pretenções de caracter contencioso: de uutra, de um bacharel em Direito, formado em Coimbra, reclamando contra decisões judiciarias que não o admittiram á advocacia, e o Conselho assim o decidiu, não só por tratar-se do direito de postular em juizo, sujeito a condições de exercicio, como porque, por sua natureza, uma tal reclamação, além de revestir o caracter recurso, é evidentemente extranha ás attribuições do Conselho.

Outras questões de menor monta foram estudadas, discutidas e resolvidas; mas, por seu minimo interesse "para nós, deixo de referil-as.

Emfim, o Diario Official, de 5 a 13 de Agosto, publicou as actas das sessões do Conselho. de 1911 .

Faculdade de Direito de $\$$. Paulo, 19 de Agosto

$O$ director interino, João Mendes de Almeida Junior. 